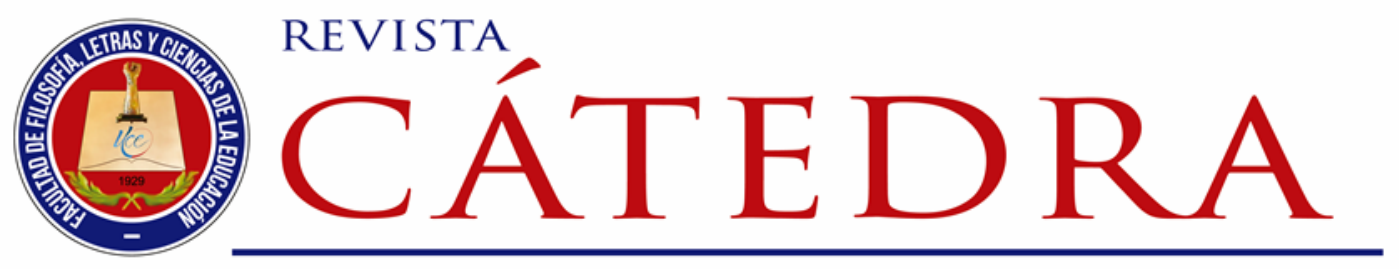

\title{
El concepto de culpa desde los principales referentes de la filosofía contemporánea
}

\author{
The concept of guilt from the main references of \\ contemporary philosophy
}

\author{
Floralba Aguilar-Gordón \\ Universidad Politécnica Salesiana, Quito, Ecuador \\ faguilar@ups.edu.ec \\ https://orcid.org/0000-0002-9886-6878
}

\author{
Karol Batallas-Almeida \\ Universidad Politécnica Salesiana, Quito, Ecuador \\ kbatallas@est.ups.edu.ec \\ https://orcid.org/0000-0001-8754-151X
}

(Recibido: 15/03/2021; Aceptado: 19/03/2021; Versión final recibida: 11/05/2021)

Cita del artículo: Aguilar-Gordón, F. y Batallas-Almeida, K. (2021). El concepto de culpa desde los principales referentes de la filosofía contemporánea. Revista Cátedra, 4(2), 106120.

\section{Resumen}

El manuscrito discute sobre el concepto de culpa desde Nietzsche, Heidegger, Jaspers y Ricouer como principales referentes de la filosofía contemporánea que han abordado este tema. En el artículo se reflexiona acerca de las distintas concepciones de culpa y su relación con el sujeto moderno, su existencia, la trascendencia y la responsabilidad. En una época tecnificada, dominada por la tendencia utilitarista y consumista, la producción en serie y la enajenación que vive el ser humano respecto a sí mismo, se hace indispensable repensar en torno a la autenticidad, a la individualidad y a la subjetividad en contextos singulares como el nuestro. La metodología utilizada para la estructuración de este documento se respalda en las principales directrices de la investigación cualitativa, se apoya en la revisión bibliográfica, el análisis de textos, y consecuentemente, el método hermenéutico para la interpretación de las teorías, categorías, principios, doctrinas y concepciones. El artículo se encuentra estructurado en cuatro apartados: El primer apartado presenta una discusión sobre el concepto de culpa y el nacimiento de la conciencia desde la perspectiva nietzscheana. El segundo apartado se refiere al concepto de culpa en la filosofía de Martín

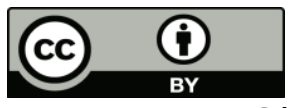


Heidegger, explica la función que cumple la culpa en el esclarecimiento del sentido del ser. El tercer apartado realiza una exposición sobre la relación entre el concepto de culpa y trascendencia según Karl Jaspers. Finalmente, el cuarto apartado, indaga sobre la relación planteada por Ricouer acerca del concepto de culpa y la responsabilidad.

\section{Palabras clave}

Autenticidad, culpa, existencialismo, filosofía contemporánea, responsabilidad, trascendencia.

\section{Abstract}

The manuscript discusses the concept of guilt from Nietzsche, Heidegger, Jaspers and Ricouer as the main referents of contemporary philosophy that have addressed this issue. The article reflects on the different conceptions of guilt and its relation to the modern subject, its existence, transcendence and responsibility. In a technified era, dominated by the utilitarian and consumerist tendency, mass production and the alienation that the human being lives with respect to himself, it becomes indispensable to rethink about authenticity, individuality and subjectivity in singular contexts such as ours. The methodology used for the structuring of this document is based on the main guidelines of qualitative research, it is supported by the bibliographic review, the analysis of texts, and consequently, the hermeneutic method for the interpretation of theories, categories, principles, doctrines and conceptions. The article is structured in four sections: The first section presents a discussion on the concept of guilt and the birth of conscience from the Nietzschean perspective. The second section refers to the concept of guilt in Martin Heidegger's philosophy, explaining the function of guilt in the clarification of the meaning of being. The third section makes an exposition on the relationship between the concept of guilt and transcendence according to Karl Jaspers. Finally, the fourth section explores the relationship raised by Ricouer on the concept of guilt and responsibility.

\section{Keywords}

Guilt, contemporary philosophy, existentialism, transcendence, responsibility, authenticity.

\section{Introducción}

El manuscrito discute sobre el concepto de culpa desde Nietzsche, Heidegger, Jaspers y Ricouer como principales referentes de la filosofía contemporánea que han abordado este tema. En el artículo se reflexiona acerca de las distintas concepciones de culpa y su relación con el sujeto moderno, su existencia, la trascendencia y la responsabilidad. En una época tecnificada, dominada por la tendencia utilitarista y consumista, la producción en serie y la enajenación que vive el ser humano respecto a sí mismo, se hace indispensable repensar en torno a la autenticidad, a la individualidad y a la subjetividad en contextos singulares como el nuestro.

El concepto de culpa es un término polisémico, tiene varias significaciones que provienen de ámbitos diferentes como el ético, el jurídico, el moral y el existencial propiamente dicho; así mismo, existe algunas connotaciones, diferencias y similitudes en cuanto a su sentido y significado, la concepción más destacada se relaciona con el término deuda. En el pensamiento existencialista, la culpa es el núcleo de la existencia, pues ella cumple la función de reclamar la autenticidad del ser. El artículo tiene como objetivo reflexionar sobre el concepto de culpa desde el existencialismo en relación con el sujeto, la trascendencia y la responsabilidad. 


\section{El concepto de culpa y el nacimiento de la conciencia en Nietzsche}

Nietzsche en su investigación sobre los sentimientos morales, realizó un recorrido sobre el origen de tales sentimientos, así como su evolución a lo largo del tiempo. En un comienzo, este pensador, basándose en los trabajos de quienes el mismo denomina "psicólogos ingleses" y en especial apoyado en Paul Ree, llegó a la conclusión de que todos los conceptos morales no guardan un origen divino, sino que más bien son el resultado de las distintas evoluciones de la civilización, son producto de la vida social del ser humano. Para Nietzsche (2011), el análisis sobre los sentimientos morales de estos psicólogos ingleses posee "un gusto perverso por lo raro, lo dolorosamente paradójico, lo problemático y absurdo de la existencia" (p. 50), puesto que demuestran que, tras todos los conceptos, el ser humano los ha revestido con un aura divina o santa, en donde más bien se encuentran cuestiones biológicas, instintivas y animales.

Asimismo, para Nietzsche (2011), "esos investigadores que miran el alma con microscopio" (p. 50) se han acercado a una verdad distinta de lo ya enseñado por la tradición religiosa, pues esta verdad expresa lo más humano de los sentimientos morales es una verdad "simple, áspera, fea, nauseabunda, acristiana, amoral" (p. 50). Esta opinión de Nietzsche se basa en el hecho de que esos investigadores sostuvieron que los actos altruistas han permanecido dentro de las distintas civilizaciones por razones utilitarias, es decir, las acciones generosas, desinteresadas contribuyeron a la supervivencia de los grupos humanos y se mantuvieron en la memoria de los pueblos por ser funcionales a los instintos gregarios (a los grupos de personas), de manera que no son acciones que tengan algún valor en sí mismo o algún significado transcendental, sino que son acciones que por medio del hábito y su utilidad se han reproducido a lo largo de la historia.

Por otra parte, si bien Nietzsche elogia el trabajo de estos "psicólogos ingleses", sostiene que su investigación sobre el origen de los sentimientos morales ha sido buscado en un lugar erróneo, puesto que para Nietzsche (2011) el concepto de bondad no surgió de algún consenso social y tampoco de ningún sentido utilitario, sino que más bien "fueron los propios 'buenos', esto es, los nobles, los poderosos, los individuos de posición y de sentimientos elevados quienes se vieron y se valoraron a sí mismos y a sus actos como buenos" (p. 51). De tal manera que Nietzsche en contraposición de la opinión común, defendió la idea de que los conceptos de bueno y malo fueron empleados en su inicio para marcar una división jerárquica entre los individuos nobles, superiores y los individuos serviles, mediocres, vulgares, débiles.

De acuerdo a Nietzsche (2011) las clases nobles se caracterizan por "su actitud indiferente y despreciativa de la seguridad, del cuerpo, de la vida, del bienestar" (p. 68), y además presentan ciertas características que en la modernidad serían observadas como perversas, entre las cuales se encuentran una tendencia hacia el placer intenso en la conquista y en la guerra, una tendencia hacia la crueldad y el goce en la destrucción, y lo que es más importante, una tendencia hacia la creación de valores auténticos y originales, llegando incluso a sostener que este tipo de individuos se encuentran destinados a representar lo mejor de la humanidad, es decir la humanidad auténtica; son individuos que se encuentran más allá del bien y del mal, y cercanos al ideal del "súper hombre", es decir, de aquel ser humano que ha superado todo tipo de esquemas, que ha superado lo más bajo de la humanidad, que responde únicamente a su "voluntad" y cuya meta es lo excepcional, esto es la creación de valores más elevados que aquellos que caracterizan a la vida cristiana signada por el conformismo, la mediocridad y la sumisión. 
Además, para este tipo de personas tiene poca importancia la utilidad de las acciones, ya que son individuos que no se fijan como dice Nietzsche en "el cálculo prudencial y utilitario" (p. 51), son aquellos que por su propia naturaleza y constitución física tienden a derrochar fuerzas, se concentran en la acción, y desbordan de vida e instintos poderosos. Por el contrario, los seres humanos inferiores, serviles y mediocres constituyeron históricamente todo lo contrario a los sujetos superiores que se denominaron a ellos mismos como "buenos". De tal manera que, en el origen de los sentimientos morales, fueron estos los mediocres quienes por su propia naturaleza tendían hacia el ahorro, la prudencia y la utilidad, y que a ojos de los seres superiores representó todo lo bajo y lo "malo" de la sociedad.

Lo antes expuesto se evidencia en la explicación de Nietzsche quien sostiene que el origen de los sentimientos morales no debe ser encontrado en algún tipo de consenso social que se reprodujo a lo largo de la historia por su valor utilitario, sino que más bien debe ser buscado en la lucha histórica que se dio entre la clase de los señores y la clase de los esclavos, entre la clase de los guerreros y la clase de los sacerdotes; ya que fue una lucha histórica que hasta la actualidad permanece y se expresa en nuevas formas de dominio y sumisión. Entre estas nuevas formas de dominio y sumisión, Nietzsche mira las continuas luchas por el igualitarismo social, el cual en su opinión es un disfraz que las clases débiles emplean en su intento de domesticar a las clases dominantes (Nietzsche, 2011).

Nietzsche se dio cuenta que en el transcurso de los siglos el ganador de esta lucha fue la clase de los sacerdotes, una clase que se caracteriza por una constitución física débil, pero cuyas deficiencias son sutilmente escondidas en el tipo de vida contemplativa, ascética y espiritual que viven. Los sacerdotes, bajo esta apariencia subhumana que tratan de brindar, generan en el pueblo cierto temor, ya a que son individuos que se presentan a sí mismos como los receptores y transmisores de los mensajes divinos, que se distinguen por hábitos que asustan a los demás como la autoflagelación y otros tipos de autoagresiones. Además, la vida ascética que lleva esta clase de individuos, genera dentro del público sensaciones de misterio y de profundidad, siendo este artificio uno de los principales recursos para triunfar sobre las clases guerreras.

Es importante recalcar que tanto la clase de los guerreros como de los sacerdotes buscan a decir de Nietzsche, el dominio bajo distintos medios; los guerreros lo hacen a través de la conquista y la fuerza, los sacerdotes por medio de distintos artificios, y al cual se añadirían otros como los remordimientos que se exponen sobre el pueblo a través de su visión del pecado, y el que es más importante: el amor y la crucifixión de sus mártires. Asimismo, el tipo de medios empleados por la clase de los sacerdotes responde a una venganza contra las clases dominantes; dirigiéndose a aquella rebelión de los esclavos que Nietzsche observa en el triunfo del cristianismo.

De acuerdo con Nietzsche (2011) "la rebelión de los esclavos en la moral se inicia cuando el propio resentimiento se vuelve creador y produce valores: el resentimiento de aquellos individuos a quienes les está impedida la verdadera reacción" (p. 63). Esta rebelión representa una explosión de todos los resentimientos acumulados por las clases serviles, puesto que esta clase al no poseer la fuerza para combatir directamente contra las clases dominantes, planeó en lo más profundo del ser distintas formas espirituales para vengarse contra aquellos que les sometieron por la fuerza.

De hecho, para Nietzsche, aquello que los pueblos denominan espíritu o conciencia es sinónimo del triunfo de las clases sacerdotales, debido a que estas clases en su búsqueda de artificios para triunfar y dominar, emplearon conceptos espirituales para alterar las fuerzas de las clases dominantes. De tal forma, el triunfo de los esclavos se basó en trasladar la 
verdadera lucha hacia un plano espiritual, hacia el interior de los individuos, naciendo bajo esta nueva forma de lucha: los conceptos de conciencia, culpa y remordimiento. De aquí en adelante, la lucha entre amos y esclavos aconteció más profunda, más espiritual y más sutil.

Se debe recalcar que esta batalla una vez que adquirió un tono más profundo y espiritual, trajo también una inversión en la jerarquía y división de los conceptos morales; una inversión por la que el concepto de bueno empleado por los individuos superiores y fuertes para caracterizarse a sí mismos, fue asumido y re inventado bajo un sentido totalmente diferente por la clase de los individuos inferiores. La inversión de la escala de los valores empleada por las clases esclavas se basó en una nueva división entre lo bueno y un concepto que ellos mismos introdujeron, el concepto de "malvado", un concepto que según Nietzsche nació del resentimiento y del odio de las clases serviles.

Así, Nietzsche (2011) analiza que entre el concepto de bueno empleado originalmente por las clases superiores y el concepto de las clases serviles, existe una gran diferencia: "el primero es una creación posterior, algo adicional, un color complementario; el segundo en cambio, es el original, el inicio, la verdadera acción en la concepción de una moral de esclavos" (p. 67), y más adelante señala que la antítesis radical del concepto de bueno empleado por las clases serviles, es un concepto que designa a todo aquello que tiene la apariencia de perversidad, ocio, placer por la destrucción y crueldad, es decir: lo malvado, y el cual es una designación empleado por la clase de los esclavos para vengarse y desacreditar las propiedades de las clases nobles.

Una vez que Nietzsche llega a esta conclusión, no solo se encuentra autorizado para señalar que la jerarquía de los valores de la modernidad se basa en una inversión que inició con la rebelión de los esclavos y que es perfectamente identificable en el platonismo y en la filosofía ética de Kant, sino para afirmar que la cultura tal como es entendida en la actualidad es la materialización de la misma rebelión y el resultado de una falsificación de la naturaleza humana. La cultura se ha convertido en manos de las clases de los esclavos en un instrumento para domesticar las fuerzas de aquellos individuos selectos que presentan una salud desbordante y unos instintos de dominio y conquista. Así mismo, la cultura bajo la rebelión de los esclavos se ha convertido en algo contrario a la vida, a su inocencia y en general contraria a su natural inclinación hacia la creación de valores nuevos y originales, en tanto, valores como la igualdad, la misericordia o el auto sacrificio que caracterizan a la cultura, son signos de instintos debilitados, de una voluntad de nada que a su vez se encuentra presente en los valores cristianos.

Entonces, teniendo en cuenta estos aspectos sobre la rebelión de los esclavos y el origen, así como la evolución de los sentimientos morales, se puede indicar que el concepto de culpa en términos generales expresa una deuda que un sujeto contrae con un acreedor. Este concepto evolucionó al igual que la cultura; en sus orígenes se buscaba únicamente algún castigo físico que merecía un sujeto que había cometido un perjuicio contra otra persona y únicamente después que las batallas entre clases sacerdotales y clases guerras se interiorizaron en el sujeto, adquirió el concepto de culpa su sentido actual.

De acuerdo con Mejía (2002), en la dinámica entre el castigado y el castigador existía una lógica de placer y displacer; el goce que provocaba el castigar fue una forma de recompensación por parte del perjudicado, ya que según Nietzsche (2011) "hacer sufrir produce bienestar, puesto que el perjudicado cambiaba el daño, así como el displacer que éste le producía, por un extraordinario contra-goce: el hacer sufrir" (p. 75). Estos castigos que en principio fueron solamente físicos, lentamente se interiorizaron bajo la forma de una batalla espiritual, naciendo de este modo una serie de remordimientos morales junto con la 
conciencia. De este modo, la deuda de las primeras sociedades humanas se internalizó en la conciencia, dando nacimiento al concepto de culpa.

La rebelión de los esclavos introdujo el concepto de culpa para triunfar sobre la clase de los señores; emplearon este concepto para establecer una deuda insuperable entre el ser humano y un ente superior, y de esta forma asegurarse el dominio total sobre la cultura y la historia universal. La religión cristiana, como expresión de las clases sacerdotales, fue utilizada para asegurar el triunfo de estas clases serviles; una religión levantada sobre el mito del pecado original, en un mito que estableció una deuda insuperable entre el ser humano y Dios, un mito en el que se funda toda forma de remordimiento y sentimiento de culpa. Así lo señalan algunos estudiosos como Rojo (2017) "toda religión está fundada principalmente en la idea de pecado, o sea, el sentimiento de culpa que se experimenta por no poder dar cumplimiento a las normas prescritas. Sin esta concepción, la religión pierde todo su sentido" (p. 121).

Además, desde la perspectiva del cristianismo, la culpa traduce la deuda ontológica que el ser humano tiene con Dios, pues el ser humano no ha creado el universo, ni a sí mismo, sino que es Dios el creador de todas las cosas. En la literatura filosófica personalista se pueden encontrar argumentos como los de Mounier, para quien el ser humano a diferencia de los animales experimenta incertidumbre no solo por el origen de todas las cosas, sino por la permanencia del mundo que habita. Y en esta necesidad por la búsqueda de certezas, se presenta la idea de Dios como una de las más aceptadas. En consecuencia, el ser humano tiene una relación de dependencia con Dios, es decir con su creador, de manera que, si el hombre comete faltas morales, le falla a Dios, y en esto consiste la culpa, en este sentido, el hombre tiene una deuda ontológica con Dios, ya que es él quien le ha dado al 'ser', la posibilidad de existir y su posibilidad de trascender (Mounier, 2000).

Según Elders (1983) el concepto de culpa refiriéndose en una forma teológica, da cuenta de "una perturbación voluntaria de la ordenación del hombre hacia Dios" (p. 173) y que se expresa en la falta de responsabilidad moral. De tal manera, aquella rebelión de los esclavos que inició contra las clases señoriales y que paulatinamente adquirió una sutileza espiritual, hasta acabar en una lucha interior, fue desde su comienzo una rebelión planificada, que empleó medios como la cultura y la religión para domesticar los impulsos y los instintos de los individuos fuertes. La conciencia junto con la culpa nace bajo la forma de una batalla espiritual empleada por los esclavos, y fue precisamente este sentimiento el que Nietzsche combatió a lo largo de su vida, pues su propósito era el de recuperar la inocencia del ser humano; no es una novedad que la figura última de las tres transformaciones que expuso Nietzsche en su obra Así habló Zaratustra, sea precisamente un niño (luego del camello y del león).

En el siguiente apartado se expone el concepto de culpa desde el existencialismo de Jaspers y de Martín Heidegger. La diferencia entre las formas de plantear el concepto de la culpa en estos autores consiste en que la culpa para Jaspers tiene un aspecto psicológico y moral que debe ser descubierto; mientras que, para Heidegger, la culpa cumple con una función de esclarecimiento del sentido del ser.

\section{La culpa y el esclarecimiento del sentido del ser según Heidegger}

Antes de empezar con el desarrollo de este acápite, es importante indicar que la filosofía existencialista de Heidegger surge como una respuesta a los acontecimientos trágicos de las dos guerras mundiales del siglo XX. El tema central de la filosofía de Heidegger es la 
existencia; uno de los motivos por los que ésta se convirtió en la preocupación principal de este autor fue la enajenación que experimentó el hombre en el siglo XX. Según Prini (1957), la enajenación del hombre fue denunciada por el existencialismo bajo:

[...] el doble aspecto de una pérdida de caracteres propiamente personales de la existencia, dentro de las sugestiones e imposiciones siempre más vinculadas a una colectividad anónima y en el automatismo de una vida y de un mundo siempre más rigurosamente organizado del progreso técnico (p. 10).

En este nuevo mundo surgieron las masas o las multitudes, que según Heidegger (2003) constituían el dominio impersonal del colectivismo, mientras que para Marcel (1964) este acontecimiento reflejaba "la sofocante tristeza de un mundo organizado según la idea de función" (p. 74). En este contexto, surge el existencialismo heideggeriano bajo un sentimiento de descontento profundo por un hombre que no se encontraba así mismo en el mundo que el mismo construyó. Entonces la tarea era averiguar el sentido de la existencia y reivindicar la autenticidad del individuo. Para lo cual, Heidegger dio un papel especial al concepto de culpa.

Heidegger en su análisis de aquello que se encuentra por encima de lo óntico, es decir de todo aquello que se encuentra por fuera de las cuestiones cotidianas, políticas y éticas, se concentró en la estructura del Dasein, la estructura de lo que es más propio e inmediato al ser humano: su existencia. Para lo cual, desarrollará, como indica Redondo (2001):

[...] un tipo de conceptuación que en la historia del pensamiento sólo
había aparecido con motivo de la expresión de un determinado tipo de
experiencia. Se trata de la conceptualización con la que en la tradición
había tratado de dar cuenta y expresión de si la búsqueda de si por parte
de un sujeto que se siente caído, extrañado, perdido y disperso y que trata
de recolectarse con el fin de centrarse en lo más propio y genuino de sí,
de estar de verdad consigo, y que por tanto ha de empezar buscándose
(p. 27).

La búsqueda de Heidegger sobre la estructura de la existencia inicia con una problematización del sentido y la autenticidad del Ser-ahí (Dasein), dando la forma de una conceptualización articulada a la experiencia de lo que Heidegger denomina estructura "confesional" del sujeto o estructura de la subjetividad de quien se busca a sí mismo, indica también que el ser humano es un ente a quien le interesa su ser, un ser que puede saberse y experimentarse en la autenticidad o en la inautenticidad, entre la posibilidad de conocerse a sí mismo o perderse (Heidegger, 2003).

Por otro lado, como indica Redondo (2001), la estructura del Dasein tiene "un mundo articulado como un espacio de relevancias, remisiones y significatividades, en que el ente se nos muestra en lo que es, no siendo ese mundo sino una determinación de la existencia misma" (p. 28). Esto quiere decir que el mundo es una modalidad más del ser del Dasein, ya que el mundo es un espacio que funda el mismo ser humano a través de su existencia; es el espacio donde la existencia se relaciona consigo misma, con los otros y con los objetos. En términos de Heidegger, el análisis existencial revela que el Dasein aparece bajo la forma de ser-en-el-mundo. El mundo es un espacio construido por el Dasein, donde las cosas aparecen en una red de significados y relevancias.

El ser humano se proyecta en un mundo que existe sin significados previos y que únicamente encuentra sentido a partir de la existencia. Desde este punto de vista, el ser 
humano se encuentra arrojado a la existencia; él es el único que tiene el deber de hacerse cargo de sí mismo. De frente a un mundo que no tiene significados previos, la existencia como indica Redondo (2001) "se aprehende asentada sobre la posibilidad de la absoluta imposibilidad de sí, la de la muerte, y esa es la posibilidad irrebasable y aquella en que cada uno no puede ser sustituido por nadie" (p. 29).

Por lo tanto, el ser humano se enfrenta a la angustia y aparecen dos constituyentes de la estructura del Dasein: el cuidado y la culpa. Por una parte, el cuidado es definido por Heidegger como el momento de proyección y facticidad en el que la existencia se abre al mundo. El ser humano en su condición con el mundo tiene que relacionarse con objetos; se preocupa con las cosas, muestra apego y adicción a ellas (Heidegger, 2003). Sin embargo, la existencia una vez que se arroja al mundo de las cosas deja de ser auténtica. En el cuidado y en la preocupación de las cosas, el Dasein se encuentra lejos de sí, se encuentra ocupado con las actividades que la costumbre dicta y que todos los seres humanos hacen, como pensar, leer o escoger.

El ser humano frente a la angustia puede optar libremente por la preocupación de las cosas cotidianas, huyendo así de la angustia, o por el abismo existencial que se abre con la pregunta ¿para qué? El ser humano tiene la capacidad de elegir; puede elegir entre preocuparse por la cotidianidad y así vivir en la opresión de lo próximo, o puede optar por la posibilidad de poder ser según Heidegger, y de este modo atender al llamado de la conciencia que en el fondo dice al ser humano que la existencia se dirige hacia la muerte. Así también lo explica Ballbé (1964):

\section{Nuestra libertad consiste en elegir entre ser en la opresión de la proximidad, es decir, en la individualidad impersonal, o asumir el riesgo de peregrinar, reconociendo nuestra finitud, como testigos de una trascendencia que se oculta continuamente, pero que ofrece la posibilidad irrealizable de la existencia auténtica (p.1).}

Vivir en la cotidianidad y en la preocupación por las cosas es optar por la existencia inauténtica, mientras que el reconocimiento de la finitud humana es una posibilidad para la existencia auténtica y para trascender. En esta decisión libre surge la culpa, y por esto se la considera según Ballbé (1964) como "el núcleo de la existencia" (p. 1). La culpa existencial debe ser distinguida de la culpa cualitativa. La primera se refiere a la huida de las posibilidades de poder ser, es decir de la autenticidad. La segunda se refiere a la culpa que el ser humano experimenta en la cotidianidad, cuando comete algún error en lo referente al valor de la convivencia y que han sido pactados convencionalmente.

El ser humano escapa de las preguntas sobre el sentido del ser, ya que provocan angustia y llevan algún tipo de crisis existencial. La sociedad ofrece múltiples formas para evitar este encuentro con la angustia, que se presentan como incentivos que comparten los seres humanos en su conjunto. Además, el ser humano cuando afronta la crisis existencial, siente el peso de su libertad, de ser alguien singular y diferente de los demás. Para escapar de la angustia que implica la libertad y la individualidad, desea nuevamente ser integrado a la sociedad, como si se tratara de un cordero que ha perdido su rebaño.

La sociedad crea continuamente mecanismos para evitar la angustia: centros de diversión, espectáculos, series. Lo importante es formar parte de las masas. El ser humano en lugar de elegir por sí mismo, prefiere sumergirse y perderse entre las masas. En otras palabras, el surgimiento de las masas es una forma de descarga colectiva frente a la angustia, frente a la posibilidad de ser. Para Ballbé (1964) de "las múltiples formas de descarga del yo individuales y colectivas - la más simple consiste en el ocultamiento o represión de la 
vivencia de la culpa, con lo cual se logra eliminar del campo de la conciencia la falta cometida" (p. 5)

Cuando el ser humano adopta esta forma de existir pierde su individualidad, convirtiéndose en un sujeto anónimo que vive en la inautenticidad. La culpa existencial surge precisamente en esta decisión que el ser humano ha tomado, pues le recuerda la renuncia de su posibilidad de poder ser y la responsabilidad que el debió haber tenido consigo mismo. Así mismo lo indica Acevedo (2013), la culpa "tiene un propósito ontológico fundamental; es decir, su meta es aclarar una dimensión del ser-ahí con la finalidad de preparar el terreno para plantear con suficiencia la pregunta que interroga por el ser y su sentido" (p. 56)

Para Heidegger (2003), la culpa se encuentra en las profundidades del mismo ser, siendo la voz de la conciencia, quien señala al hombre su culpabilidad. Este pensador por medio de la analítica trascendental, que es un estudio fenomenológico, encontró que la culpa constituye una estructura fundamental de la existencia humana y que la conciencia la descubre. Según Acevedo (2013), este llamado de la conciencia muestra al "ser-ahí inmerso en la cotidianidad de término medio o mediana dominado por el ser o uno arrojado en el mundo y caído en las habladurías, la avidez de novedades, la ambigüedad y el temor" (p. 58) y exige de él, abandonar la impropiedad para asumirse como sí mismo.

Es necesario recalcar que este llamado no lo hace la conciencia a partir de discursos, ya que según Heidegger (2003) "la conciencia habla única y constantemente en el modo de callar" (p. 321). La conciencia recuerda al hombre que es culpable por perderse a sí mismo en la cotidianidad, por hacer de la existencia un negocio ocupado con asuntos del mundo, en lugar de asumir su finitud, ya que la aceptación de esta dimensión fundamental del ser humano implica hacerse cargo de sus posibilidades como existencia auténtica. Una vez, que el ser humano, acepta su finitud, atiende al llamado de la conciencia y se dispone para la resolución. En palabras de Heidegger (2003):

El estado-de-abierto del ser-ahí implícito en el querer tener conciencia resulta constituido [...] por el encontrarse de la angustia, por el comprender como proyectarse sobre el más propio ser-culpable y por el habla como silenciosidad. Esta señalada abertura propia, atestiguada en el Dasein mismo por su conciencia- el silencio proyectarse, dispuesto a la angustia, sobre el más propio ser-culpable- lo llamamos la resolución. La resolución es un señalado modo de la abertura (p.154).

Sin embargo, según Acevedo la resolución no implica la desaparición de la culpabilidad, pues a pesar de que se opte por la autenticidad, la culpa pervive (Acevedo, 2013). Si bien, el aspecto positivo de la resolución consiste en la aceptación de las limitaciones de la existencia, en su carácter finito y en el rechazo de las ilusiones que ofrece la sociedad; la culpa permanece, porque el ser humano frente a la angustia de la existencia, tiende nuevamente a olvidarse de sí mismo.

\section{La culpa como situación límite según Jaspers}

Uno de los conceptos centrales de la filosofía de Jaspers pertenece a las 'situaciones límites', las cuales según este autor tienen por función despertar la conciencia, similar a la función que Heidegger atribuyó al concepto de culpa. Según Jaspers, la culpa es una de estas 'situaciones límites' que al igual que el suicidio, la lucha o la enfermedad son acompañadas por algún tipo de crisis existencial. La importancia que Jaspers atribuye a estas 'situaciones límites' consiste en que tienen una función positiva para la constitución de la individualidad, ya que ponen al sujeto frente a sí mismo. En estas ‘situaciones límites' el sujeto experimenta 
la fragilidad de su condición finita, y por este detalle son situaciones que despiertan al sujeto de la cotidianidad, señalándole sus posibilidades como existencia y la necesidad de ser uno mismo, ser lo que se es. En este punto es importante tener en cuenta lo que dijo Nietzsche (1951) frente a su enfermedad, ya que la enfermedad como la culpa son dos situaciones límites que descubren la finitud humana:

[...] todo el sentido de los terribles dolores físicos a que he estado sometido se encuentra en que gracias a ellos fui arrancado de una concepción errónea — es decir, cien veces demasiada baja- del cometido de mi vida. Y como cuento por naturaleza entre los hombres modestos, son precisos los medios más violentos para hacerme volver a mí mismo (p. 265).

Como se puede ver, el hombre que desea resolverse consigo mismo, encuentra en la enfermedad una oportunidad, siente el llamado de su conciencia, quien le exige ser el mismo. La enfermedad de Nietzsche fue una situación límite del teatro trágico de la vida según lo consideró Unamuno (1983) quién presenta al ser humano la oportunidad de pensarse como un proyecto, como una posibilidad, como el único dueño de su destino. La enfermedad si es aceptada y atendida, provoca en el sujeto una crisis existencial que lo despierta de su estado inerte, de aquel estado en el que estaba fuera de sí mismo, ocupado con cosas que lo alejaban de la angustia y que lo convertían en un sujeto anónimo que se perdía en la masa. Aquel que rechaza las situaciones límites está condenado a rechazar su existencia auténtica. Esta huida según Ballbé (1964):

[...] conducen al fracaso de la posibilidad de ser sí mismo. La aparición de la culpa, que se manifiesta como crisis existencial, nos acusa de la deserción cometida. La irreversibilidad temporal y el horizonte de la muerte, dan sentido a la angustia ante la condenación que exige, perentoriamente, el arrepentimiento y la conversión a la autenticidad. El sentido de esta crisis define lo que denominamos culpa existencial (p. 4)

Esto quiere decir que el ser humano se encuentra a sí mismo en el horizonte de la muerte, pues frente a ella tiene que declarar cual es el sentido de su existencia, es decir ¿por qué y para qué? Son estas preguntas las que determinan el estilo de vida de cada hombre que ha decidido ser el mismo. Por otra parte, la culpa a diferencia del castigo social, es individual, subjetiva y representa el remordimiento que genera el daño causado a un valor que el ser humano lo estima como único e intrínseco a sí mismo. Y este valor, es el mismo sujeto y su existencia.

La culpa existencial exige la transformación del sujeto en existencia, autenticidad y el llamado de la conciencia lo realiza a través de signos en lugar de palabras. En el fondo, lo que expresa la conciencia por medio de la culpa es una búsqueda continua del porqué, y el cual quizá nunca encuentre sentido, a menos que el ser humano auténtico, libre e individual lo defina. Es decir, en el fondo se encuentra la nada, que incita al individuo a inventarse un sentido y crearse un proyecto. Por este motivo, es correcto lo que indica Ballbé (1964), quien considera que "la culpa es reveladora de nuestra deuda originaria y mueve al hombre a peregrinar incesantemente en busca de una verdad que siempre se oculta y asoma tras cada negación" (p. 10). Esto quiere decir que el ser humano tiene una deuda inquebrantable consigo mismo, que se la presenta cuando se olvida de sí mismo. En esto consiste la culpa existencial.

La culpa como situación límite indica que la acción humana trae consecuencias inevitables. Los seres humanos al no contar con una capacidad que les permita predecir certeramente 
las consecuencias de sus acciones en el futuro, pueden sentir la culpa. Entonces, la culpa es inseparable a la vida y se relaciona estrechamente con su carácter finito. Las decisiones que forman parte de la existencia, pueden terminar lastimando o hiriendo a alguien. Es importante indicar que la omisión de acción también es una decisión que puede tener consecuencias inevitables. De esta forma, el ser humano está condenado a experimentar la culpa.

La idea de culpa de Jaspers puede conectarse con la percepción que tiene Sartre (1992) sobre la libertad humana, ya que el ser humano está condenado a ser libre, condenado a enfrentar sus responsabilidades; así lo señala en sus palabras "cuando decimos que el hombre es responsable de sí mismo, no queremos decir que el hombre es responsable de su estricta individualidad, sino que es responsable de todos los hombres" (p. 33). Así mismo, cabe señalar que la culpa además de pertenecer a los seres humanos, corresponde a la época que ellos mismos han creado. Jaspers (1992) al pronunciarse sobre la culpa y la responsabilidad de Alemania en la segunda guerra mundial, indica que:

\section{[...] en mí situación cargo yo con la responsabilidad de lo que acontezca por no haber intervenido; si yo puedo hacer algo y no lo hago, yo soy culpable de las consecuencias de mi abstención: Así, pues, actúe o no, ambas conductas tienen consecuencias; en todos los casos incurro irremediablemente en la culpa (p. 120).}

A pesar de que la culpa sea una situación límite de la cual el ser humano no puede escapar, existe una posibilidad de trascender a partir de ella, que Jaspers encontró en la filosofía y en la comunicación. La filosofía según este autor es comunicación continua, una actividad por la que se llama al otro; cuyo principal objetivo es indagar y aclarar el sentido de la existencia. Esto consiste en que entre las personas que filosofan sobre asuntos que les compete, no existe alguna autoridad. De esta forma, la comunicación entre semejantes permite entender al otro como un sujeto libre, cuyo deber es realizarse.

El ser humano tiene por objetivo ser lo que es; es el único ser que es una posibilidad, en su libertad se realiza a sí mismo y en la comunicación se trasciende junto con otros sujetos libres. Así, si la culpa es una situación límite que obliga al ser humano a escoger por su autenticidad, se podrá afirmar que la comunicación permite esta posibilidad. Este aspecto no fue desconocido por Sartre, pues se preocupó por la importancia que impone el dialogo con el otro.

Entonces, se puede resumir que la culpa es una forma de despertar la conciencia de su adormecimiento, que se expresa a través de una crisis existencial que pone al sujeto frente a sí mismo. Este planteamiento trae un problema relacionado con la responsabilidad y la vida de los otros, ya que la culpa desde esta perspectiva parecería que es una situación individual y egoísta, que no guarda relación alguna con el otro, aspecto que lleva al siguiente apartado en el que se revisa la relación entre culpa y responsabilidad desde la perspectiva de Ricoeur.

Ricoeur en su libro "Finitud y culpabilidad" (2004) trata sobre la labilidad del ser humano hacia el mal, a partir de la investigación sobre la estructura de la realidad humana que generalmente es dividida entre acciones voluntarias y acciones involuntarias. Cabe recalcar que su investigación sobre la labilidad del ser humano lo hace por medio del estudio de símbolos que se encuentran a la base del pensamiento occidental. De esta manera Ricoeur (2004) partiendo del 'lenguaje de la confesión' trata de entender el contenido de palabras simbólicas que provienen de la tradición religiosa como mancha, pecado, culpabilidad. De esta forma, para encontrar el sentido de la culpa es importante según este autor "una 
exégesis del símbolo, que requiere ciertas reglas para descifrar, es decir una hermenéutica" (p. 14).

Ricoeur (2004) mediante este procedimiento llega a la conclusión de que la labilidad hacia el mal se expresa en el acto de confesión de una conciencia religiosa. Segovia (2015) explica, la confesión "es el tono con que el ser humano va confesándose a sí mismo el aprendizaje del ser, que tanto es placentero como doloroso" (p. 137). A pesar de que el dolor y el temor son distintos, se desarrollan de forma paralela, pues ambos se encuentran relacionados con la conciencia culpable. El primero por relacionarse con una acción considerada como prohibida, y la segunda por encontrarse determinada por algún tabú de lo sagrado.

De este análisis hermenéutico se recogen dos aspectos importantes. El primero consiste en que la labilidad hacia el mal es una posibilidad que refleja la propia experiencia trágica de la existencia, porque en ella se reconocer la posibilidad de fallar. El segundo se refiere a que la libertad es posible cuando se toma responsabilidad de la propia culpa. En la asimilación y en el arrepentimiento se encuentra la posibilidad de reconstruirse. Esta práctica de carácter religioso es antigua y aún determina la conciencia humana.

En el contexto contemporáneo, según Lenis (2015) "frente a la objetivación excesiva de la culpabilidad que ha implicado la judicialización de los procesos penales" (p. 69), es importante considerar la experiencia subjetiva de la culpa, viéndola como un sentimiento fundante para la re significación moral. La imputación significa valorar moralmente al sujeto bajo ciertos términos de trascendencia y razón, pues tal como indica Ricoeur (2004) el razonamiento jurídico "no es un razonamiento empírico, sino un principio trascendental. Significa que todos los otros conmigo, antes de mí, después de mí, son yo como yo" (p. 271).

Para Ricouer, la imputación jurídica tiene un principio trascendental, que se basa en la preservación de la igualdad del yo con los otros tomados como yo es. Esto quiere decir, que el sujeto tiene capacidad y determinación libre. El individuo visto de esta forma, se supone que tiene intencionalidades éticas como el deseo de una vida buena, el respeto de las instituciones y un conocimiento sobre lo que está permitido de aquello que está prohibido. Por esto, la razón cumple una función importante en la responsabilidad.

De estas consideraciones se puede afirmar que la imputación atiende tanto a la agencia del individuo como los referentes morales, así también lo explica de Lenis "de la consideración de un agente que puede a la de un agente que debe" (p. 71). Además, según Ricoeur (2002) en el proceso de la imputación participa la memoria (ya que esta brinda testimonio sobre la acusación), códigos penales y las practicas que definen a un determinado grupo social, por lo que la imputación es una experiencia que comparten en común el sí mismo y los otros. La imputación depende de esta dinámica entre el sí mismo y los otros, convirtiéndose este otro en el juez de las acciones morales.

La culpa para Ricoeur (2004) es la consecuencia de la violación de los preceptos sociales y es acompañada por la desaprobación social y la denuncia. La culpa para este autor es una carga o un peso, siendo el otro, un espejo donde el sujeto se asimila como culpable. Como se puede ver, la culpa en Ricoeur es semejante a las observaciones de Sartre y Jaspers, ya que, a pesar de ser una situación individual, implica la existencia de los demás. Sin embargo, la diferencia está en que Ricoeur se ocupa con otros sentimientos que se encuentran tras la culpa, como: la vergüenza, el remordimiento y el arrepentimiento.

La culpa solo surge cuando existe reconocimiento, es decir implica algún tipo de confesión, quedando la imputación y la responsabilidad condicionadas por este deseo. Esto quiere decir, que el reconocimiento de la culpa es necesario para las reparaciones y para que la 
imputación genere en el individuo la responsabilidad con sus acciones. Al respecto, Lenis (2015) ha sugerido que:

[...] la fuerza afectiva del reproche, del autorrechazo, se hace fundamental en este sentirse, saberse y decirse culpable. La imputación se queda en la dimensión de la exterioridad si el sí mismo no se adscribe la responsabilidad por unas acciones cuyas consecuencias han hecho daño (p. 75).

Si el imputado no se siente culpable, es imposible que valore un posible re-significación ética y menos que asuma un sentido responsable. Ser responsable y ser culpable son dos cosas distintas, pues tal como expresa Ricoeur "la conciencia de responsabilidad no es más que un apéndice de la conciencia de verse abrumado anticipadamente por el peso del castigo" ( $p$. 261). Por otro lado, la responsabilidad, según Ricoeur, se desarrolla por medio de tres dimensiones temporales, ya que se encuentra relacionada con el futuro (anticipación de las consecuencias de la acción), el pasado (como una deuda) y el presente (aceptarse hoy como responsable). Esto quiere decir, que el ser humano es un ser lo suficientemente reflexivo para considerar las implicaciones de sus acciones.

\section{Conclusiones}

En este artículo se discute en principio el concepto de culpa desde el pensamiento de Nietzsche, encontrando que este concepto en su significado más original se refiere a una deuda que en las primeras sociedades humanas se basó en una dinámica entre placer y displacer, entre goce y dolor, pues aquel que cometía algún perjuicio tenía que pagar con su propio dolor físico, y lo cual representó un goce para el acreedor. Además, el concepto de culpa como pudo identificar Nietzsche se relaciona con el nacimiento de la cultura y con el triunfo de la rebelión de los esclavos, en tanto, la culpa surge como una forma empleada por estas clases para domesticar los instintos de conquista y dominio de las clases fuertes, es decir, de aquellas clases guerreras que desbordaban de fuerza.

Luego de este análisis, se discutió el concepto de culpa bajo el concepto del existencialismo heideggeriano. Para Heidegger la culpa forma parte de la estructura del Dasein, surge frente a la angustia de la existencia y expresa la posibilidad de ser auténtico. Específicamente, la culpa según Heidegger se presenta como un llamado de la conciencia que reclama al individuo ser sí mismo. A su vez, este llamado de la conciencia expresado en la culpa fue comparado con las situaciones límites de Jaspers, encontrando que ambos conceptos tienen en común la función de despertar la conciencia de su letargo.

En el pensamiento de Jaspers se pudo identificar que la culpa implica a todos los individuos, de tal forma que la acción o la omisión tienen consecuencias sobre los demás. Por lo que, la culpa es irremediable y tuvo que ser pensada en su relación con la responsabilidad. Bajo este objetivo, se reflexiona sobre el concepto de culpa en términos de la hermenéutica de Ricoeur, llegando a la conclusión de que el sujeto que comete algún perjuicio y que asume la culpa de su acción, tiene la capacidad para tomar responsabilidades y re construirse éticamente. 


\section{Bibliografía}

Acevedo, J. (2013). El sentido heidegggeriano de la culpa y la melancolía. Revista de filosofía, $55-66$.

Ballbé, R. (1964). Reflexiones sobre el sentido de la culpa. Revista de Psicología, 13-26.

Elders, L. (1983). El sentimiento de culpabilidad según la psicología, la literatura y la filosofía modernas.

Gabriel , M. (1964). La dignidad humana. Barcelona: Atalaya.

Heidegger, M. (2003). El ser y el tiempo. México: Fondo de cultura económica.

Jaspers, K. (1967). Psicología de las concepciones del mundo. Madrid: Gredos.

Jaspers, K. (1989). Filosofía de la existencia. México: Fondo de cultura económica.

Jaspers, K. (1992). Filosofía. Tomo II. México: Fondo de cultura económico.

Lenis, J. (2015). Avatares de la conciencia moral. Imputación, culpa y responsabilidad. Discusiones filosóficas, 69-85.

Mejía, M. (2002). Culpa y Deuda. Affectio Societatis, 1-7.

Mounier, E. (2000). El personalismo. Madrid: Taurus.

Nietzsche , F. (2011). Genealogía de la moral. EDIMAT: Madrid.

Nietzsche, F. (1951). Obras completas. México: Aguilar.

Nietzsche, F. (2012). Así hablaba Zaratustra. Barcelona : Plutón.

Prini, P. (1957). Las tres edades del existencialismo. Monteagudo.

Redondo , M. (2001). Cuidado y culpa en ser y tiempo de M.Heidegger. Lapsus, 21-32.

Ricouer, P. (2002). Del texto a la acción. Ensayos de hermenéutica II. México: Fondo de cultura económica.

Ricouer, P. (2004). Finitud y culpabilidad. Madrid: Trotta.

Rojo, F. (2017). Tratado del bien y del mal. La ética como filosofía primera. Universidad Pontificia Comillas, Madrid: Facultad de Ciencias Humanas y Sociales.

Sartre, J. (1992). El humanismo es un existencialismo. Barcelona: Edhasa.

Segovia, N. (2015). Finitud y culpabilidad de Paul Ricoeur. Puebla: Univversidad Iberoamericana Puebla.

Unamuno, M. (1983). Del sentimiento trágico de la vida. Madrid: Bruguera. 


\section{Autores}

FLORALBA AGUILAR-GORDóN es Postdoctora en Investigación Cualitativa. Doctora en Filosofía. Doctora en Investigación y Docencia. Magíster en Educación, mención Educación Superior. Magíster en Tecnología aplicada la educación. Magíster en Educación a Distancia. Experto en Analítica del conocimiento. Especialista en Planificación Curricular y Organización de Sistemas de Educación a Distancia. Diplomado Superior en Currículo y Didáctica. Diplomado Superior en Transformación Educativa. Diplomado Superior en elearning. Diplomado Superior en Investigación Educativa. Diplomado Superior en Fundamentos de la Educación a Distancia e Investigación. Diplomado Superior en Aprendizaje Cooperativo. Diploma Superior en Tecnología, Gerencia y Liderazgo. Tutora internacional acreditada por la Universidad Católica de Brasilia. Licenciada en Filosofía. Licenciada en Ciencias Sociales, Políticas y Económicas. Abogada.

Actualmente es docente titular, coordinadora del Grupo de Investigación en Filosofía de la Educación (GIFE) y Editora Jefa de la Revista Sophia: Colección de Filosofía de la Universidad Politécnica Salesiana del Ecuador. Colabora en el programa semipresencial de la Universidad Central del Ecuador. Docente en programas de maestría y doctorado en prestigiosas universidades nacionales e internacionales. Se desempeña como Miembro del Consejo Editorial de importantes revistas de Ecuador, España, Colombia, Uruguay, Chile, México, Cuba, Costa Rica, Panamá. Perú.

KAROL BATALLAS-ALMEIDA es Licenciada en Educación con itinerario en Filosofía de la Universidad Politécnica Salesiana del Ecuador. Investiga acerca de temas y problemas relacionados con la educación y con la filosofía de la educación. 